\title{
Reflexões sobre a política nacional de formação de professores a distância e o enfraquecimento da EaD pública pela Universidade Aberta do Brasil (UAB)
}

\author{
Eucidio Pimenta Arruda* \\ Universidade Federal de Minas Gerais
}

Resumo Este artigo tem como objetivo problematizar o desenvolvimento da EaD pública por meio do sistema Universidade Aberta do Brasil (UAB), discutir como a formação de professores se torna a opção mais ofertada na $\mathrm{EaD}$ brasileira, tanto privada quanto pública. Procura analisar, de forma crítica, os caminhos trilhados pela $\mathrm{EaD}$ pública, apontando seus desafios, limites e possibilidades. Indica ainda trilhas possíveis para que a $\mathrm{EaD}$ pública deixe de ser reconhecida como parte de programas de governo e possa ser construída como política de Estado, em uma perspectiva de indissociabilidade entre ensino, pesquisa e extensão, próprias de uma formação universitária. Procuramos ainda discutir análises acerca da situação em que se encontra o campo profissional da docência, bem como problematizamos a pouca necessidade de se formar mais profissionais por meio de programas específicos, sem que hajam políticas de fortalecimento profissional da categoria. Por fim, problematizamos como a manutenção da UAB é responsável por fragilizar e dificultar o desenvolvimento e consolidação da EaD como modalidade regular do ponto de vista acadêmico e financeiro nas instituições públicas federais de ensino superior.

PALAVRAS-CHAVE: Formação de professores; Sistema Universidade Aberta do Brasil; Educação a distância. 


\title{
Reflections on the national policy of distance teacher training and the weakening of the public EAD by the Open University of Brazil (OUB)
}

\begin{abstract}
This article aims to problematize the development of public distance education (DE) through the Open University of Brazil system (OUB), to discuss how teacher training becomes the most offered option in the Brazilian DE, both private and public. It seeks to critically analyze the paths taken by the public DE, pointing out its challenges, limits and possibilities. It also indicates possible ways in which the public DE can no longer be recognized as part of government programs and can be constructed as a State policy, in a perspective of inseparability between teaching, research and extension, typical of a university education. We also sought to discuss the situation of the professional field of teaching, as well as discuss the lack of need to train more professionals through specific programs, without policies to strengthen the professional category. Finally, we discuss how the maintenance of the Open University of Brazil (OUB) is responsible for weakening and hindering the development and consolidation of $\mathrm{DE}$ as a regular modality from the academic and financial point of view in the federal public institutions of higher education.
\end{abstract}

KEYWORDS: Teacher training; Open University system of Brazil; Distance education.

\section{Introdução}

Apesar da educação a distância (EaD) ser conhecida no Brasil pelo menos desde o início do século XX, essa modalidade, no ensino superior, reconhecida somente em 1996 pelo art. 80 da Lei de Diretrizes e Bases da Educação (LDB). Arruda (2011) afirma que até então a história da $\mathrm{EaD}$ pautava-se pela oferta de cursos para jovens e adultos (ensino fundamental e médio) e os chamados cursos livres (dentre os quais destacam-se aqueles ofertados por instituições como o Instituto Universal Brasileiro (IUB).

Em 1998 houve a primeira regulamentação da Educação a Distância, por meio do Decreto no 2494, que foi substituído pelo Decreto no 5622 de 2005 e novamente atualizado pelo Decreto no 9054 de 2017. É interessante observar o movimento histórico das regulamentações, que passa por uma ampliação da modalidade em 1998, a criação de elementos dificultadores em 2005 e uma abertura ampla em 2017, facilitando, inclusive, as possibilidades de oferta de $\mathrm{EaD}$ na educação básica regular.

Os decretos anteriormente citados atenderam a anseios históricos de setores público e privado, sobretudo porque, conforme Moore e Kearsley (2010) e Formiga (2009) afirmam, do ponto de vista histórico, a EaD é potencializadora democratização do acesso à educação em todos os níveis, sobretudo em países de dimensões continentais, como é o caso do Brasil. 
Reflexões sobre a política nacional de formação de professores a distância e o enfraquecimento da EaD pública pela Universidade Aberta do Brasil (UAB)

Nessa linha argumentativa, cabe salientar que o discurso da democratização é o grande impulsionador da $\mathrm{EaD}$ pública brasileira, sobretudo pela incapacidade governamental de promover uma ampliação intensa da educação superior pública na modalidade presencial, ainda que dados do Censo da Educação Superior de 2017 demonstrem ter dobrado o número de universitários em instituições públicas de ensino superior (IPES) nos últimos 15 anos.

$\mathrm{Na}$ história da $\mathrm{EaD}$ pública em nível superior, as primeiras incursões na modalidade ocorreram por meio de iniciativas localizadas, tais como o Projeto Veredas em Minas Gerais (2002), o Consórcio Cederj (2000), no Rio de Janeiro e a Universidade Federal de Mato Grosso (UFMT), considerada pioneira na implementação da modalidade $\mathrm{EaD}$ nas universidades públicas, por meio da criação do curso de Pedagogia no final dos anos 1990.

É, sobretudo, a partir de 2006 que o Brasil inicia uma grande transformação nas políticas públicas em $\mathrm{EaD}$ ao fomentar a criação e consolidação de um programa de EaD nacional, denominado Sistema Universidade Aberta do Brasil (UAB), por meio do Decreto no 5800 de 2006.

O sistema UAB configura-se em um grande programa de parcerias entre o governo federal, por meio da CAPES, dos estados e municípios, por meio de polos de apoio presencial e de IPES de maneira a ampliar a oferta coordenada de cursos a distância, promovendo a interiorização da educação superior pública (BRANCO e PEIXOTO, 2018, p. 667).

Se, por um lado, a UAB se constitui no primeiro grande programa de $\mathrm{EaD}$ em nível nacional (ARRUDA, 2015), responsável por um grande movimento promotor da democratização do ensino superior no interior do Brasil, por outro, conforme apresentaremos ao longo desse artigo, possui grande contribuição para o pouco desenvolvimento institucional da $\mathrm{EaD}$ nas universidades públicas, além de ajudar a consolidar resistências e pouco desenvolvimento legislativo em relação à regulamentação da $\mathrm{EaD}$ como modalidade regular da educação superior pública. Pensar na consolidação significa pensar em uma modalidade de educação que independa de programas governamentais específicos e, o que se observa, é um recrudescimento do programa UAB, sobretudo com a atual política nacional de formação de professores, lançada em 2017 e que, a depender do planejamento apresentado pelo Ministério da Educação, dará fôlego ao sistema UAB por, pelo menos, mais uma década.

Este artigo tem como objetivo problematizar o desenvolvimento da $\mathrm{EaD}$ pública por meio do sistema Universidade Aberta do Brasil, discutir como a formação de professores se torna a opção mais ofertada na $\mathrm{EaD}$ brasileira, tanto privada quanto pública. Procura analisar, de forma crítica, os caminhos trilhados pela $\mathrm{EaD}$ pública, apontando seus desafios, limites e possibilidades. Indica ainda trilhas possíveis para que a $\mathrm{EaD}$ pública deixe de ser reconhecida como parte de programas de governo e possa ser construída como política de Estado, em uma perspectiva de indissociabilidade entre ensino, pesquisa e extensão, próprias de uma formação universitária. 


\section{Dimensões da formação de professores como argumento para a constituição do Sistema Universidade Aberta do Brasil nas instituições públicas de ensino superior}

A Educação a distância universitária em instituições públicas, como política nacional, inicia-se com o sistema Universidade Aberta do Brasil em 2006, por meio do decreto $\mathrm{n}^{\circ} 5800$. Conforme visto anteriormente, haviam projetos específicos e localizados, sejam por iniciativas governamentais ou de instituições, dentre os quais destacamos o Projeto Veredas, em Minas Gerais (2002-2005), o Consórcio Cederj (2000) no Rio de Janeiro (que funciona até hoje sob financiamento da UAB) e a Universidade Federal do Mato Grosso (UFMT), que lançou um curso de Pedagogia ainda no final dos anos 90 em parcerias com municípios do estado. Criado pelo Decreto n. 5800 de 2006 e implantado em 2007 por meio do curso de Administração em consórcio com o Banco do Brasil (ARRUDA e ARRUDA, 2015) o sistema UAB caracteriza-se por um consórcio que envolve municípios estados (que oferecem os polos de apoio presencial), instituições públicas de ensino superior (federais, municipais e estaduais) que ofertam os cursos e é regulamentado e financiado pela Coordenação de Aperfeiçoamento de Pessoal (CAPES).

Como política pública, o sistema UAB constitui-se como um programa de governo, ainda que ele tenha sobrevivido a várias gestões. $\mathrm{O}$ programa foi criado para atender a uma demanda específica e localizada - a saber, a formação de professores. Desde sua criação e, inclusive, na atual política nacional de formação de professores, o foco sempre foi direcionado à docência na educação básica pública. $\mathrm{O}$ argumento maior consiste na necessidade de se formar mais professores para atender às metas dos planos nacionais de Educação (BRASIL, 2001 e BRASIL, 2014)), que consistem em ampliar o número de professores que possuem formação em nível superior e o número de professores que ministram aulas na área de sua formação.

É interessante perceber que aquilo que move o surgimento do programa - a formação de professores - é também o que pode garantir-lhe a longevidade que já possui. $\mathrm{O}$ sistema UAB completou 10 anos de efetivo início ${ }^{1}$ e, se se considerar a situação atual do nível de formação docente para a educação básica, é possível inferir que o programa ainda possui um relativo fôlego nos próximos anos. Haja vista que os dados do Censo da educação básica tem mostrado que os números de docentes formados em nível superior, bem como os de professores com formação na área em que atual tem sofrido poucas modificações.

O percentual de professores da educação básica com nível superior em licenciatura, por exemplo, subiu de 69\% para 74,4\% entre 2013 e 2017. Já o percentual de professores do ensino fundamental e médio que possuem nível superior compatível com a área do conhecimento em que lecionam vai de $40 \%$ a $46,9 \%$ e de $49 \%$ a $54,9 \%$, respectivamente, de acordo com os dados do Censo da Educação básica analisados entre 2013 e 2017.

O que se percebe nesses dados é a problematização necessária acerca da forma como uma política pública é conduzida. O sistema UAB aparece como pro- 
Reflexões sobre a política nacional de formação de professores a distância e o enfraquecimento da EaD pública pela Universidade Aberta do Brasil (UAB)

grama responsável pela melhoria dos índices de formação de professores, mas, dadas as inúmeras circunstâncias, possui pouco impacto na ampliação dos quadros docentes. Ferreira e Clímaco (2015) demonstram que até 2014 o sistema UAB havia formado pouco mais de 20 mil alunos de licenciatura. Dados da Diretoria de Educação a Distância - DED/CAPES de 2017 mostram que até 2017 o sistema UAB havia formado cerca de 182 mil alunos, considerando-se cursos de extensão, especialização, bacharelado e licenciatura. Se considerarmos um total de 600 mil vagas preenchidas, pode-se apreender que há ainda um fosso significativo para minimizar os problemas da formação docente e que o sistema UAB não tem como, na condição de programa e pelas características que lhe são pertinentes, atender ao objetivo com o qual fora criado e é reforçado pela política nacional de formação de professores de 2017.

Dessa forma, é possível enunciar questões que se tornam pertinentes: investir significativos recursos públicos em formação de professores é a melhor política para a melhoria da educação básica brasileira? Ou há de se incluir as dimensões como condições de trabalho, salários, valorização e outros elementos que impliquem no lugar que a docência ocupa na sociedade brasileira?

Essa questão é importante, sobretudo quando analisamos outros dados da educação a distância no Brasil. As instituições privadas promoveram, nos últimos dez anos, um processo de redimensionamento de modalidade de ensino nas vagas ofertadas na licenciatura. Em 2007 haviam 25\% das matrículas das instituições privadas na licenciatura e, em 2016, esse número salta para 60\% do total de matrículas. Só para se comparar, o percentual de matrículas no bacharelado na modalidade a distância em instituições privadas é de apenas 10\%, de acordo com dados do Censo da Educação Superior de 2016.

Depreende-se, portanto, que a licenciatura a distância, mais do que uma necessidade formativa para atender a demandas educacionais brasileiras, é percebida como um modelo de negócios nos quais pode-se oferecer cursos superiores com significativa redução de custos e mínimas resistências por conselhos ou associações de classe $^{2}$.

As resistências às licenciaturas a distância são desconstruídas sobretudo por um discurso "politicamente correto" de que é necessário formar professores com a máxima urgência, e que não há tempo hábil para se fazer isso por meio da educação presencial. Tal afirmativa apresenta-se com argumentos sólidos, visto que, somente no âmbito do atendimento à formação mínima em nível superior, precisaríamos de cerca de 300 mil novos professores para universalizarmos a formação correta dos professores da educação básica (de acordo com dados do Censo Escolar de 2017.

Observa-se, por outro lado, que são formados, no Brasil, a cada ano, cerca de 250 mil docentes em nível superior (Brasil, 2017). Não existem dados muito precisos acerca do que fazem os egressos após o término do curso superior, mas é possível inferir que o argumento em defesa de se construir programas específicos a distância para formar mais professores não se sustenta, conforme veremos a seguir. 
Apesar disso, Mill (2016) salienta que o sistema UAB representou uma melhoria qualiquantitativa para a $\mathrm{EaD}$ pública, sobretudo por ter integrado a grande maioria das IPES brasileiras, apesar do mesmo autor afirmar que há uma precariedade na oferta da $\mathrm{EaD}$ que se consubstancia sobretudo pela pouca experiência de gestão da equipe condutora da UAB nas IPES.

Se, por um lado, a manutenção de programas como a UAB pode indicar positividade em relação à $\mathrm{EaD}$ ser considerada estratégica como modelo de formação pelo governo brasileiro, por outro lado, a manutenção como programa e não como política de Estado pode nos dizer sobre a importância da $\mathrm{EaD}$ na formação universitária nas instituições públicas de ensino superior.

Apesar de haver números que indicam a necessidade de se formar mais professores, acreditamos que outros elementos precisam ser incorporados para que se possa fazer uma análise mais complexa e sólida a respeito da manutenção de políticas voltadas quase em exclusividade para a formação de novos docentes, ao invés de se dedicarem a outras questões pertinentes à docência, como condições de trabalho, planos de carreira ou melhores condições salariais de entrada na docência.

Pinto (2014) afirma que historicamente o número de vagas para formação de docentes tem aumentado significativamente, enquanto que o número de alunos interessados, bem como o número de formandos tem diminuído consideravelmente. Para se ter uma ideia, na modalidade a distância, somadas as instituições privadas e públicas, chegou-se a perto de um milhão e seiscentas mil vagas, para um universo de pouco mais de 300 mil interessados e pouco mais de 100 mil concluintes (INEP, 2016)

A demanda de professores gira em torno de 2,3 milhões de vagas docentes para todas as áreas, conforme dados do Censo Escolar de 2017. Pinto (2014) demonstrou em um amplo estudo dos dados do INEP e do Censo Escolar entre 1990-2010, que, à exceção de Física, Ciências e Língua estrangeira, para todos os demais componentes curriculares se formou, no mínimo, o número equivalente de vagas docentes demandadas.

É importante observar a necessidade de pesquisas mais aprofundadas que mostrem também os fluxos migratórios dos egressos nas licenciaturas, bem como as relações entre demanda e quadro de profissionais formados por região, uma vez que dados médios nacionais podem apresentar inconsistências que nos ajudem a analisar o objeto

Ao se analisar a dimensão da política pública educacionais, observa-se que existe relativa força no argumento de que a falta de professores precisa ser resolvida por meio de soluções emergenciais e rápidas - o que fortalece a $\mathrm{EaD}$ como possível "solução" ao problema apresentado, em detrimento de políticas públicas mais pertinentes, como, por exemplo, ofertas adequadas às necessidades e relacionadas às circunstâncias que fixem ou tornem a docência interessante para os profissionais, sobretudo os jovens, que tem cada vez menos procurado a área de formação, conforme demonstrado pelo próprio Ministério da Educação ao se referir às políticas nacionais de formação de professores. 
Reflexões sobre a política nacional de formação de professores a distância e o enfraquecimento da EaD pública pela Universidade Aberta do Brasil (UAB)

Tamanha é a força desse argumento, que o Ministério da Educação brasileiro lançou em outubro de 2017 a Política Nacional de Formação de Professores, em que indica o financiamento de mais de 250 mil vagas para a formação docente nas instituições públicas, além de outras 20 mil a serem financiadas nas instituições privadas por meio do pagamento integral das mensalidades pelo governo brasileiro, sem a necessidade de demonstração de condições de vulnerabilidade ou a necessidade de formação em nível superior (BRASIL, 2017).

Observa-se, portanto, que a política educacional de formação de professores possui caráter político de demonstração de preocupação governamental com a crise docente, que não se consubstancia no desenvolvimento de estudos e análises que visem compreender melhor o fenômeno da falta de professores no Brasil.

Como forma de iniciar a oferta de $\mathrm{EaD}$ em instituições públicas, consideramos que o argumento, do ponto de vista político, é razoavelmente exitoso, uma vez que encontra pouca resistência no campo educacional, apesar de associações de área conhecidas lançarem manifestos contrários à formação inicial de professores a distância, sobretudo no formato anunciado pelo MEC em 2017 (ANPED, 2017).

Além disso, é necessário compreender o contexto no qual o sistema UAB se desenvolve e que ajuda a consolidar a questão da $\mathrm{EaD}$ nas universidades. Mesmo com as precarizações e lacunas institucionais, o sistema UAB é exitoso ao potencializar a $\mathrm{EaD}$ pública em todos os estados brasileiros (HERNANDES, 2017)

O que se pode problematizar não é o êxito do programa, conforme seu objetivo proposto, mas problematizar as formas como se reforça o discurso de que a EaD é massificadora e voltada para a formação de mão-de-obra barata. Haja vista que mais de 60\% dos cursos superiores ofertados a distância por instituições privadas são de licenciaturas e, a docência é a carreira menos valorizada dentre todas com nível superior e nota-se uma tendência política pela manutenção de programas de formação de professores que podem fomentar a disponibilidade de mão-de-obra docente e fragiliza-la ainda mais.

Quando se compara os dados de matriculas e concluintes no Brasil com os países da Organização para a Cooperação e Desenvolvimento Econômico (OCDE), o Brasil possui cerca de quatro vezes a média de alunos matriculados nas licenciaturas e o dobro de concluintes (Censo da Educação Superior 2016 e Education at a Glance 2017).

Em contrapartida, de acordo com pesquisa Education at a Glance (2017) o Brasil é o país que apresenta o maior número de alunos por turma na educação básica, além dos piores salários em relação à OCDE.

Logo, é possível perceber que há a necessidade de se investigar outros motivos que levam o Brasil a ter um número de profissionais formados atuando na educação básica aquém da necessidade do país. 
Apesar dos dados direcionarem para uma compreensão de que não faltam vagas para se formar professores no Brasil, ainda assim, o único programa nacional de Educação a Distância brasileiro, o sistema UAB, mantém e reforça uma política de priorizar apenas a formação de professores.

Oliveira (2017) detectou que a maioria das pesquisas realizadas sobre a UAB versam sobre práticas pedagógicas, docência ou tutoria. Faltam análises ou discussões que direcionem para uma ampliação da $\mathrm{EaD}$ como fomentadora para a formação profissional geral e não apenas de um determinado campo profissional. Essa manutenção de discurso acerca da possível falta de professores reforça a perspectiva na qual a $\mathrm{EaD}$ cresce e se consolida no Brasil como modalidade quase exclusiva para professores. Tal leitura pode incorrer no recrudescimento da desvalorização docente na sociedade (Kallajian e Aquino (2017).

Ou seja, ao invés de ser uma política que visa atender uma ausência de professores nas escolas públicas, o investimento na ampliação das vagas para formação de professores no ensino superior pode estar vinculado a uma estratégia de ampliar significativamente o número de professores formados em número bem acima do necessário, para que se possa contar com profissionais suficientes para ocuparem os postos que cada vez mais são abandonados pelos docentes ativos.

A dificuldade, não só do governo federal, por meio da CAPES, mas também das instituições públicas que participam do sistema UAB de se redirecionar o discurso acerca da forma como a $\mathrm{EaD}$ vai ser consolidada ajuda a construir uma modalidade que atende a somente uma categoria profissional. Categoria essa que historicamente é fragilizada em todos os aspectos, o que poderia incorrer em uma leitura lacunar sobre a EaD, como se ela só fosse aceita em áreas do conhecimento com tal fragilidade. Para reforçar esse argumento, chama-nos a atenção a falta de programas governamentais voltados à ampliação da $\mathrm{EaD}$ por meio da oferta de outras frentes de formações deficitárias em nível superior no Brasil.

Encontramos, portanto, um ambiente nas instituições públicas de ensino superior, em que é propício manter a $\mathrm{EaD}$ como modalidade marginal, com todas as limitações e problemas, conforme apresentaremos no próximo tópico.

Sob a perspectiva da política educacional, observa-se que a dinâmica empreendida pelo governo brasileiro nos últimos anos fragiliza a $\mathrm{EaD}$ e o sistema UAB, ao estabelecer parâmetros bem distintos da educação presencial em uma ação temporal longeva, se comparada a outros programas de $\mathrm{EaD}$ do passado.

Acreditamos que esse duplo movimento: falta de ações fora da formação de professores e manutenção da $\mathrm{EaD}$ como programa, por meio da UAB é ajuda a fortalecer a resistência à $\mathrm{EaD}$ nas IPES e a fragilizar o seu funcionamento, resultando quase na impossibilidade de ofertas regulares amplas, de acordo com a autonomia e a política das instituições públicas. 
Reflexões sobre a política nacional de formação de professores a distância e

o enfraquecimento da EaD pública pela Universidade Aberta do Brasil (UAB)

\section{Contribuições dos programas emergenciais para a fragiliza- ção da EaD̉ nas instituições públicas federais}

Os dados obtidos para o desenvolvimento desse trabalho são oriundos da experiência do autor como partícipe do sistema UAB ao longo dos últimos dez anos e pela análise de dados obtidos junto aos fóruns de coordenadores UAB nesse período. É necessário informar que tais dados não são passíveis de constituírem quaisquer identificações de pessoas ou IPES, mas tão somente o tratamento de dados quantitativos e qualitativos obtidos nas inúmeras interações realizadas nesses anos.

Um dos primeiros problemas detectados na consolidação da $\mathrm{EaD}$ junto às IPES diz respeito a um processo lento e frágil de reconhecimento institucional da modalidade como ação regular das instituições participantes do sistema UAB. Haja vista que em 2010 instaurou-se um grupo de trabalho sobre institucionalização da $\mathrm{EaD}$, constituído sob a responsabilidade do fórum de coordenadores do sistema Universidade Aberta do Brasil e apoiado pela CAPES. Esse fórum foi descontinuado em 2012, sobretudo por não ter obtido sucesso quanto à construção de uma perspectiva política acerca da institucionalização.

Em 2017 houve nova constituição do grupo de trabalho (GT) sobre institucionalização da $\mathrm{EaD}$ nas instituições públicas de ensino superior, por meio da Portaria $n^{\circ}$ 03, de 5 de janeiro de 2017. O primeiro trabalho consubstanciou-se na aplicação de um questionário para obter respostas acerca das condições de oferta e funcionamento da EaD nas IPES.

Os dados do GT apesar de serem preliminares, buscam efetuar levantamentos estatísticos sobre a implantação da $\mathrm{EaD}$ nas instituições que fazem parte do sistema $\mathrm{UAB}$ e, dessa forma, acabam por centrar mais no sistema propriamente dito do que na dimensão da institucionalização, que deveria ser pensada de forma desatrelada à UAB.

Haja vista que mais de $70 \%$ das instituições pesquisadas não possuem oferta de $\mathrm{EaD}$ sem fomento externo (por meio da UAB, rede e-tec ou outra), o que demonstra uma dependência relativamente alta de programas específicos para a modalidade e reforçam os argumentos apresentados nesse texto.

Do ponto de vista conceitual, a EaD é compreendida como uma modalidade a ser desenvolvida por unidade gestora específica, de forma desatrelada da educação presencial. Haja vista que o termo "unidade gestora" não é utilizado para a modalidade presencial.

Essa denominação é, per se, responsável por direcionar todo um entendimento de que a Educação a Distância é desenvolvida de forma marginal, separada, das demais iniciativas educacionais das instituições públicas. Não há, por exemplo, nada que corrobore tal entendimento, uma vez que até mesmo a legislação brasileira desconstrói quaisquer perspectivas de distinções entre modalidades, na medida em que os instrumentos para criação, avaliação, credenciamento e autorização de cursos estabelecem parâmetros únicos para ambas as modalidades. 
Os dados desse documento, ao serem analisados em conjunto, direcionam para uma $\mathrm{EaD}$ ofertada por meio de fomento externo e com estrutura específica para a $\mathrm{EaD}$, desatrelada, portanto, das instâncias regulares de oferta de cursos superiores, predominantemente presenciais. Além disso, a utilização dos recursos financeiros fica a cargo das unidades gestoras de $\mathrm{EaD}$, o que desatrela a autonomia pedagógica e financeira das unidades acadêmicas que costumam ofertar os cursos superiores na instituição. Por outro lado, há uma reconfiguração de poderes no interior da IPES, pois as unidades acadêmicas passam a depender da organização das unidades gestoras de $\mathrm{EaD}$ para planejarem e desenharem seus cursos - redimensionando a autonomia universitária.

O conceito de $\mathrm{EaD}$ pública desatrelada da educação presencial potencializa os seguintes problemas de institucionalização da modalidade nas IPES:

(a) As ações de $\mathrm{EaD}$ são ainda restritas a setores, geralmente sob a responsabilidade dos coordenadores do sistema UAB nas respectivas instituições. Isso significa que as iniciativas em $\mathrm{EaD}$ dificilmente ultrapassam a indução feita pela CAPES ou outros gestores de programas, contribuindo para as assimetrias nas formas como cursos presenciais e a distância são ofertados nas universidades públicas.

(b) A formação a distância é lacunar no que diz respeito às possibilidades de imersão na pesquisa e na extensão;

(c) Ausência de mobilidade de alunos intermodalidades, ou seja, a possibilidade de alunos migrarem entre cursos presenciais e a distância, ou realizarem aproveitamento curricular por meio da realização de disciplinas em modalidade diferente da qual está matriculado.

(d) Fragilidade nas regulamentações internas das universidades, tais como normas acadêmicas, reconhecimento de encargos de professores, reconhecimento institucional dos cursos a distância e equivalência de participação nas tomadas de decisões cotidianas.

A partir dos dados obtidos e das documentações elaboradas no âmbito da $\mathrm{UAB}$, é possível inferir que existem movimentos de construção de institucionalização da EaD singular em relação à educação presencial, no sentido da construção de parâmetros qualitativos e qualitativos. Trata-se de um posicionamento político, no qual estabelecer as distinções entre modalidades serviria para fortalecer a $\mathrm{EaD}$ como modalidade específica.

Essa perspectiva pode ser vislumbrada quando, por exemplo, são construídos internamente normas que diferenciem alunos das modalidades presencial e a distância, ou se problematizem parâmetros que distanciem o trabalho docente exercido em ambas as modalidades (MILL, 2009).

A distinção da $\mathrm{EaD}$ pode ser pensada sob a ótica metodológica, didática e tecnológica, pois ela apresenta singularidades nesse campo em relação à educação presencial. A dificuldade que encontramos nas singularidades propostas é que ela busca construir parâmetros tão diferentes que acabam por caracterizar a EaD como uma modalidade marginal, uma vez que ela precisa ter a maioria dos percursos distintos. 
Reflexões sobre a política nacional de formação de professores a distância e o enfraquecimento da EaD pública pela Universidade Aberta do Brasil (UAB)

A setorização de oferta de $\mathrm{EaD}$ é um desses exemplos de singularização que enfraquece a modalidade. Em primeiro lugar, fortalece a separação entre presencial e a distância, pois presume que há a necessidade de as modalidades serem discutidas e construídas separadamente. Desconfigura as estruturas institucionais historicamente estabelecidas, que se pautam pela autonomia e democratização das escolhas e proposições pedagógicas. Em geral, a setorização da $\mathrm{EaD}$ no âmbito de programas governamentais como o sistema UAB cria uma dependência de indução externa e, como os tempos dos recursos financeiros são distintos (e bem mais velozes) dos tempos acadêmicos, o risco de ocorrer atropelos institucionais e de haver centralização nas decisões sobre quais cursos abrir ou não é significativamente alto.

Do ponto de vista da formação universitária, a perspectiva apresentada ao aluno de uma IPES, constitui-se majoritariamente de experiências de ensino, uma vez que os incentivos financeiros, como bolsas específicas para pesquisa e extensão são inexistentes como política pública das agências de fomento brasileiras. As instituições que promovem a pesquisa e a extensão aos alunos de $\mathrm{EaD}$ geralmente o fazem por meio de estrangulamento financeiro de recursos anteriormente vinculados a cursos presenciais, em vista da inexistência desse recurso para a modalidade a distância.

Dados do Censo da Educação superior de 2016 mostram que a faixa etária média do aluno ingressante da $\mathrm{EaD}$ é de aproximadamente 30 anos, dez anos a mais do que os alunos da educação presencial. Já a idade média dos concluintes é de 35 anos, exatamente 10 anos a mais do que alunos da outra modalidade. Os alunos da EaD possuem outras especificidades como: serem casados com filhos, já estarem, em sua maioria, no mercado de trabalho, possuírem renda familiar inferior. A permanência do aluno da EaD é, portanto, um grande desafio, pois todos os dados demonstram que os obstáculos para continuar os estudos é alto.

Ocorre que inexistem políticas públicas para manter o aluno matriculado em instituições públicas - na verdade há o inverso --, uma proibição de utilização de recursos financeiros para apoio ao aluno da $\mathrm{EaD}$. Haja vista que o Programa Nacional de Assistência Estudantil (PNAES), não permite que os recursos sejam direcionados aos alunos da EaD, conforme pode ser observado no Decreto no 7.234 , de 19 de julho de 2010 .

A assimetria constatada no tratamento dado à $\mathrm{EaD}$ em comparação com a educação presencial provavelmente tem implicações importantes na qualidade da formação (que é lacunar em pesquisa e extensão), em índices de sucesso e fracasso (como taxas de evasão, permanência e índices de qualidade vinculados aos resultados obtidos em avaliações disciplinares).

Isso nos leva a problematizar os argumentos mais comuns a respeito da $\mathrm{EaD}$ que tratam da suposta falta de qualidade da modalidade. Não é tarefa fácil obter parâmetros que permitam tal comparação, uma vez que as condições são consideravelmente distintas em ambas as modalidades.

Se considerarmos os mecanismos avaliativos oficiais brasileiros, podemos inferir que a qualidade do ensino é, no mínimo, a mesma. A partir de dados coletados 
no sistema de cadastro de instituições e cursos da educação superior (E-Mec) entre dezembro de 2017 e janeiro de 2018, (disponível em http://emec.mec.gov.br) pudemos perceber que os cursos a distância ofertados por instituições públicas avaliados pelo INEP possuem a mesma nota ou superior aos cursos presenciais. A avaliação do INEP considera não somente o desempenho estudantil, mas também outros fatores, como infraestrutura e corpo docente. Dessa forma, os dados obtidos abrangem os conceitos provisórios de curso (CPC) e o Conceito de Curso (CC). Foram analisados diferentes cursos, como licenciatura em Pedagogia, Matemática, Química, bacharelado em Administração, Geografia, Engenharias etc. Em todos eles as modalidades são compatíveis em termos de notas obtidas nas avaliações.

Apesar dos dados aparentemente serem positivos para aqueles que defendem a modalidade da $\mathrm{EaD}$, eles acabam por reforçar a fragilidade da modalidade nas instituições públicas, pois leva pouco em consideração a consolidação da modalidade do ponto de vista institucional e as estratégias de avaliação.

As avaliações de infraestrutura, bem como a avaliação de pessoal, na maioria das vezes, tratam de condições já existentes voltadas para o atendimento da educação presencial. Por exemplo, os laboratórios existentes, quando avaliados por equipe do INEP, já estão presentes na instituição para atendimento à educação presencial, mas acabam por serem considerados na avaliação de cursos a distância. O equívoco pode ser compreendido na medida em que as atividades presenciais com uso de laboratório ocorrem necessariamente nos polos de apoio presencial. O Decreto no 9057 de 2017 pode modificar essa situação, na medida em que potencializa o uso da estrutura da sede para a oferta de cursos a distância, mas pode potencializar também a regionalização da oferta de $\mathrm{EaD}$, uma vez que torna a instituição sede responsável por todos os polos de apoio presencial em um contexto no qual municípios e estados são, por meio de acordo de cooperação com a CAPES, os responsáveis financeiros diretos e a matriz orçamentária das universidades públicas não comportam investimento e gastos em estruturas operadas por órgãos diferentes das próprias instituições.

Já a avaliação de pessoal pode encontrar problemas semelhantes, uma vez que os instrumentos do INEP consideram os professores efetivos da instituição como aqueles responsáveis pela oferta do curso e também pelo acompanhamento e avaliação de proposições pedagógicas do curso.

Ocorre que na maioria dos cursos ofertados no âmbito do sistema UAB, os professores não são efetivos, mas provisórios, em situação de efemeridade no curso, uma vez que ele desenvolve atividades pedagógicas estritamente vinculadas ao pagamento de bolsas de professor formador (conforme portaria CAPES no 187 de 2016). Ou seja, a situação do professor é muito parecida a de professores "horistas" de instituições privadas.

Além do problema inicial, que é a constituição de um vínculo mais sólido entre o professor e o curso, as descontinuidades geradas pela fragilidade dos vínculos docentes fazem com que os cursos ofertados tenham dificuldades em estruturar-se solidamente no interior das instituições, pois eles sempre vão depender da existência de 
Reflexões sobre a política nacional de formação de professores a distância e o enfraquecimento da EaD pública pela Universidade Aberta do Brasil (UAB)

financiamento externo da CAPES para se movimentarem. Como exemplo, podemos citar a longa ausência de financiamento para oferta de novas turmas pelo sistema UAB, ocorrida entre 2014 e 2017.

Portanto, ainda que os conceitos de qualidade do INEP demonstrem resultados razoavelmente positivos para cursos $\mathrm{EaD}$ uma análise mais aprofundada irá demonstrar que os cursos não possuem professores efetivamente vinculados, mas em situação de contratos provisórios que se extinguem com o fim das bolsas definidas pelo programa.

Essa questão nos remete às fragilidades encontradas no que diz respeito às regulamentações internas das IPES sobre $\mathrm{EaD}$, que acabam por constituírem-se em maiores lacunas e dificuldades de implantação institucional da modalidade.

Conforme afirmado anteriormente, o programa UAB, apesar de ser considerado como tal, impregnou-se de tal maneira nas políticas de EaD das instituições públicas que acabou por se tornar o sinônimo de $\mathrm{EaD}$ nessas instituições, conforme pôde ser observado nas discussões ocorridas nos fóruns de coordenadores da UAB, sobretudo nos últimos cinco anos.

O problema emergente tornou-se a ampliação de ações mais voltadas para a execução de políticas ditadas por regulamentos externos de financiamento, como os decretos de pagamento de bolsas, parâmetros de custo-aluno da UAB e editais para financiamentos específicos, como softwares recentemente publicadas pela CAPES.

De maneira geral, essas iniciativas acabaram por enfraquecer as induções gerais sobre $\mathrm{EaD}$ no âmbito das IPES e do $\mathrm{MEC}$, que visem consolidar a $\mathrm{EaD}$ como política de Estado e não programa emergencial. Como resultado disso, observou-se na maioria das instituições participantes do sistema UAB a inexistência ou existência bem frágil de políticas que redimensionem a $\mathrm{EaD}$ como modalidade e construa parâmetros de comparação e reconhecimento com a modalidade presencial.

Um dos aspectos mais levantados acerca do reconhecimento da EaD nas IPES diz respeito à constituição de um tempo de duração definido para as disciplinas a distância, que permita a sua equivalência à disciplinas presenciais. A aparente falta de parâmetro é construída sob uma argumentação frágil de que a ausência física do docente na sala de aula não cria condições de comparar os trabalhos de ambos os profissionais.

O equívoco da argumentação reside na desconsideração dos tempos e movimentos pedagógicos típicos da Educação a Distância. Se, por um lado, o professor não está presente em determinados dias da semana para ministrar as aulas, por outro, ele se torna um sujeito ubíquo e desconstrói as possíveis barreiras entre quando ele começa a ser docente e quando termina, devido às atemporalidades características do trabalho docente mediado por tecnologias (ARRUDA, 2004). Tais elementos estão por demais obscuros e acabam por direcionar o professor a uma dinâmica de trabalho que se intensifica mais do que o trabalho na educação presencial, pois não há parâmetros sobre tempos de resposta a questões enviadas em fóruns de discussão por alunos, ou o 
tempo mais adequado para promover e romper interações com os alunos. O tempo do trabalho, na EaD, revoga todos os demais tempos, como o do lazer, o da família e dos outros espaços extra virtuais e torna-se o condutor de todas as ações docentes.

Portanto, em uma análise preliminar, poder-se-ia afirmar que o tempo de trabalho em uma disciplina a distância é razoavelmente superior ao tempo de trabalho na educação presencial. Ocorre que essa premissa também possui problemas, pois, conforme dito anteriormente, o tempo na educação presencial está bem delimitado pelo tempo na sala de aula e o tempo previsto para desenvolvimento de atividades relacionadas. Já o tempo na $\mathrm{EaD}$ é baseado em suposições e previsões sobre quanto tempo seria dedicado a uma ação docente que se desdobra em inúmeras atividades e interação voltadas para uma massa de alunos que desejam e almejam um acompanhamento pessoal, único.

Se se direciona a discussão sobre o tempo de trabalho para as distinções entre modalidades, dificilmente se chega a uma análise a respeito de qual seria o fio condutor da equivalência. Além disso, trata-se de uma discussão que promove uma separação bem clara entre quem trabalha em uma modalidade e quem trabalha em outra, com riscos iminentes de se construir parâmetros distintos até mesmo para a configuração do que se entende como docência na $\mathrm{EaD}$ - o que, diga-se de passagem, poderia ser razoavelmente prejudicial aos docentes devido à falta de um histórico mais intenso de participação coletiva nas discussões trabalhistas sobre o lugar da $\mathrm{EaD}$ em sua profissionalização.

Consideramos que a integração entre as modalidades, com a aparente diminuição daquilo que as diferencia e a integração daquilo que as aproxima pode se constituir no melhor percurso político para o fortalecimento da Educação a Distâncias no âmbito das instituições de ensino superior públicas. Temos, de um lado, uma modalidade plenamente consolidada, cujos parâmetros de qualidade há muito já foram forjados e, apesar das críticas possíveis, ajudaram a construir uma educação superior pública que se destaca em qualidade das instituições privadas. Portanto, a situação ideal à $\mathrm{EaD}$ parte de uma constituição de parâmetros internos que a tornem igual à educação presencial.

Não se trata de uma igualdade conceitual, mas na busca de uma equidade entre uma possível diferença que inexiste sob o ponto de vista da docência. Trata-se de uma igualdade política, que permita a ambas as modalidades desenvolverem estratégias transversais que possam desconstruir suas fronteiras.

Outro elemento que se anuncia como problemático para a constituição da $\mathrm{EaD}$ como uma modalidade efetivamente reconhecida nas instituições públicas diz respeito à documentação que regulamenta as condições de entrada e permanência de alunos nas universidades públicas.

Ainda são poucas as normas de graduação de instituições públicas em todo o Brasil que reconheçam os alunos da $\mathrm{EaD}$ dentro dos mesmos parâmetros de reconhecimento dos alunos da educação presencial (conforme levantamento prévio realizado entre agosto e dezembro de 2017 no fórum de coordenadores do sistema UAB). Os 
Reflexões sobre a política nacional de formação de professores a distância e o enfraquecimento da EaD pública pela Universidade Aberta do Brasil (UAB)

cursos fomentados pelo sistema UAB continuam sendo tratados como cursos emergenciais (de oferta única) e essa definição acaba por direcionar as instituições a uma interpretação sobre a não necessidade de se criar normas gerais que considerem todos os direitos e deveres dos alunos da $\mathrm{EaD}$ equivalentes aos alunos da educação presencial.

Dentre as perdas para alunos da $\mathrm{EaD}$, podemos citar: falta de documentação para obtenção de redução de valor do transporte público; impedimento para obter novo título em modalidade diferente ou transferência entre modalidades; pouco investimento em políticas de acompanhamento e monitoramento institucionais dos alunos da modalidade $\mathrm{EaD}$, dentre outros.

Há de se chamar a atenção de que a legislação vigente (decreto no 9057 de 2017) deixa claro que não existem distinções entre as modalidades de educação presencial e a distância, motivo pelo qual não há explicação plausível para tais limitações - uma vez que mesmo a ausência de parâmetros em normas de graduação não diminuiria o direito maior que é o do estudante ter a equivalência de título do curso, independente da modalidade.

Percebe-se, portanto, que a manutenção de programas provisórios de $\mathrm{EaD}$ pública fragilizam sobremaneira essa modalidade nas instituições públicas, pois não permitem o estabelecimento de estratégias de longo prazo que poderiam trazer à pauta de discussões as características e condições de funcionamento dessa modalidade nas instituições públicas de ensino superior.

Por fim, percebe-se que a Educação a Distância pública no Brasil está em uma trajetória complexa, mas que, do ponto de vista da política educacional e do histórico de organização do ensino superior, dificilmente a incluirá como modalidade sólida e regular, ao menos enquanto não houver um desprendimento político da $\mathrm{EaD}$ a programas de governo.

\section{Considerações finais}

Não nos é possível tecer considerações finais sobre a $\mathrm{EaD}$ pública brasileira, mas alguns indícios nos permitem analisar e construir posicionamentos acerca do lugar que a EaD ocupa na política educacional brasileira.

A EaD pública, em conjunto com a $\mathrm{EaD}$ privada, reforça a fragilidade da formação de professores, na medida em que inferem ser esta uma modalidade adequada para esse perfil de profissional, sobretudo devido à diminuição de custos.

Ocorre que esse movimento gera outras induções que são, sobretudo delicadas para as políticas de formação de professores e para o fortalecimento da própria $\mathrm{EaD}$. O entendimento que acaba por se construir é o de que à formação de professores, já desgastada e desvalorizada, resta apenas a modalidade $\mathrm{EaD}$, o que, indiretamente, leva-nos a compreender que se trata de uma modalidade que fragiliza ainda mais as licenciaturas. 
A modalidade $\mathrm{EaD}$, por outro lado, ao ser ofertada em intensidade às licenciaturas, configura-se em uma modalidade que reforça possíveis preconceitos contra a licenciatura, já fragilizada pelas políticas públicas educacionais, além de reforçar a ideia de que tal modalidade não seria propícia a outras formações em nível superior com maior poder de defesa de seus grupos organizados (conselhos, associações etc.).

Observa-se ainda que tanto o MEC quanto a CAPES, ao manterem e reforçarem a política de ampliação da $\mathrm{EaD}$ à formação inicial e continuada de professores, acaba por restringir a modalidade apenas a esses campos específicos e deixam transparecer uma interpretação acadêmica de que o governo brasileiro não tem um posicionamento consolidado acerca dessa modalidade e que só a impõe aos grupos menos resistentes - no caso, os professores.

Poucas foram as modificações regulamentares e institucionais que pudessem inserir a $\mathrm{EaD}$ em um patamar de, ao menos, ser considerada igual à educação presencial. Na verdade, a falta de esforço nesse sentido resultou em uma marginalização significativa da $\mathrm{EaD}$ nas instituições públicas de ensino superior.

Ainda que tenhamos já dez anos de políticas públicas em EaD no Brasil, não é exagerado afirmar que pouco se avançou institucionalmente em relação ao fortalecimento dessa modalidade. Na verdade, observamos o contrário - a ampliação de movimentos que, à despeito da legislação, constroem barreiras à $\mathrm{EaD}$, tais como as restrições postas ao PNAES ou a ausência de financiamento regular para vagas públicas ofertadas a distância.

As considerações aqui propostas direcionam para um caminho pouco provável, que seria uma grande mudança na política educacional, que reconfigurasse do ponto de vista da legislação educacional, o financiamento da educação a distância no interior das instituições federais de ensino superior, pois assim, seria possível à essas instituições pensarem em sair da caixa imposta pela CAPES, qual seja, a de formar apenas professores na modalidade a distância.

Nesse sentido, advogamos que o fim do sistema UAB, apesar de todos os pontos positivos que ele representou, sobretudo por colocar a $\mathrm{EaD}$ como modalidade ofertada por IPES, é condição ideal para que outros modelos e outras reflexões acerca da forma como a EaD será incorporada nas instituições federais de ensino superior possam ser contempladas.

O futuro de uma $\mathrm{EaD}$ pública, provavelmente, passa pela desconstrução completa dos programas nessa modalidade atualmente existentes e a sua substituição por uma política de estado que inclua a indissociabilidade entre ensino, pesquisa e extensão como força motriz da modalidade a distância pública.

\section{Referências}

ANPED - Associação Nacional de Pós-Graduação e Pesquisa em Educação. Manifesto das entidades educacionais sobre a política de formação de professores anunciada pelo MEC. outubro de 2017. Disponível em http://www.anped.org.br/news/manifestacao-das-entidades -educacionais-sobre-politica-de-formacao-de-professores-anunciada. Consultado em março de 2018. 
Reflexões sobre a política nacional de formação de professores a distância e o enfraquecimento da EaD pública pela Universidade Aberta do Brasil (UAB)

ARRUDA, Durcelina Ereni Pimenta. Dimensões da aula e das práticas pedagógicas na educação superior presencial e a distância. 2011. 147 f. 2011. Tese de Doutorado. Dissertação (Mestrado em Ciências Humanas) -Universidade Federal de Uberlândia, Uberlândia.

ARRUDA, Eucidio Pimenta. Ciberprofessor: novas tecnologias, ensino e trabalho docente. FUMEC/Autêntica, 2004.

ARRUDA, Eucidio Pimenta; ARRUDA, Durcelina Ereni Pimenta. Educação à distância no Brasil: políticas públicas e democratização do acesso ao ensino superior. Educação em Revista, v. 31, n. 3, 2015.

BIELSCHOWSKY, C. E. \& Masuda, M. O. Diplomação na Educação Superior a Distância. EmRede, Revista da Educação a Distância, v. 5, n. 1., 2017

BRANCO, Juliana Cordeiro Soares e PEIXOTO, Maria do Carmo de Lacerda. Sistema Universidade Aberta do Brasil. In: MILL, Daniel Ribeiro Silva (org.). Dicionário crítico de educação e tecnologias e de educação a distância. Dicionário. CAMPINAS, Papirus, 2018

BRASIL Decreto no 9057 de 25 de maio de 2017. Regulamenta o art. 80 da LDB. Disponível em: <http://www.planalto.gov.br/ccivil_03/_Ato2015-2018/2017/Decreto/D9057.htm>. Consultado em: 10 fev. 2018

BRASIL, Lei no 10.172, de 09 de janeiro de 2001. Aprova o Plano Nacional de Educação e dá outras providências. Disponível em http://www.planalto.gov.br/CCIVIL_03/Leis/LEIS_2001/ L10172.htm>. Consultado em: 15 ago. 2018.

BRASIL, Lei no 13.005 de 25 de junho de 2014. Aprova o Plano Nacional de Educação e dá outras providências. Disponível em http://www2.camara.leg.br/legin/fed/lei/2014/lei-13005-25junho-2014-778970-publicacaooriginal-144468-pl.html. Consultado em: 28 ago. 2018.

BRASIL. Censo da Educação Superior, 2016.

BRASIL. Decreto 5800 de junho de 2006, Institui o sistema Universidade Aberta do Brasil. Disponível em: <http://www.planalto.gov.br/ccivil_03/_ato2004-2006/2006/decreto/d5800. htm>. Consultado em: 10 fev. 2018.

Brasil. Decreto n. 9.057, de 26 de maio de 2017. Diário Oficial da União, Poder Legislativo, Brasília, 25 maio 2017.

BRASIL. Decreto no 2494 de 10 de fevereiro de 1998. Regulamenta o art. 80 da LDB. Disponível em: <http://portal.mec.gov.br/seed/arquivos/pdf/tvescola/leis/D2494.pdf>. Consultado em: 10 fev. 2018

BRASIL. Decreto no 5622 de 19 de dezembro de 2005. Regulamenta o art. 80 da LDB. Disponível em: <http://www.planalto.gov.br/ccivil_03/_ato2004-2006/2005/decreto/d5622.htm>. Consultado em: 10 fev. 2018

BRASIL. Decreto no 7.234, de 19 de julho de 2010. Dispõe sobre o Programa Nacional de Assistência Estudantil (PNAES). Disponível em: <https://www.planalto.gov.br/ccivil_03/_ ato2007-2010/2010/decreto/d7234.htm>. Consultado em: 25 fev. 2018.

CAPES - Coordenação de Aperfeiçoamento de pessoal de nível superior. ATUAB. Fórum permanente dos coordenadores do sistema UAB (acesso restrito). Disponível em: <https:// atuab.capes.gov.br>. Consultado em: 15 mar. 2018.

CAPES. Coordenação de Aperfeiçoamento de Pessoal de Nível Superior. Portaria no 03, de 5 de janeiro de 2017. Cria grupo de trabalho para institucionalizar a UAB junto às IPES. Disponível em: <http://www.capes.gov.br/images/stories/download/legislacao/09012017-PORTARIA-N-3-DE-5-DE-JANEIRO-DE-2017.pdf>. Consultado em: 18 fev. 2018.

FERREIRA, Marcello. E CLÍMACO, João Carlos Teatine de Souza. Políticas públicas em Educação a Distância: o sistema da Universidade Aberta do Brasil. In: FREITAS, Maria Teresa Menezes, ARRUDA, Eucidio Pimenta e ARAÚJO, Sarah Mendonça de. Na tessitura da distância: entre políticas, docência e tecnologia na EaD. Uberlândia: EDUFU, 2015 
FORMIGA, Marcos; LITTO, Fredric M. Educação a distância: o estado da arte. São Paulo, 2009.

HERNANDES, Paulo Romualdo. A Universidade Aberta do Brasil e a democratização do ensino superior público. Ensaio: Avaliação e Políticas Públicas em Educação, v. 25, n. 95, p. 283-307, 2017.

INEP - Instituto Nacional de Estudos e Pesquisas Educacionais Anísio Teixeira. Sinopse estatística da Educação Superior - 2016. Disponível em: <http://download.inep.gov.br/informacoes_estatisticas/sinopses_estatisticas/sinopses_educacao_superior/sinopse_educacao_superior_2016.zip>. Consultado em: 01 ago. 2018.

INEP - Instituto Nacional de Estudos e Pesquisas Educacionais Anísio Teixeira. Sinopse estatística da Educação básica - 2017. Disponível em: <http://download.inep.gov.br/informacoes_ estatisticas/sinopses_estatisticas/sinopses_educacao_basica/sinopse_estatistica_educacao_basica_2017.zip>.Consultado em: 01 ago. 2018.

KALLAJIAN, Gustavo Cibin e AQUINO, Orlando Fernandez. Implicações da tecnologia digital no trabalho docente: sua expressão na literatura científica atual. In: AQUINO, Orlando Fernandez e BORDOLANZA, Ana Maria Esteves. Trabalho docente e práticas pedagógicas de formação: uma visão da pesquisa atual. Uberlândia: EDUFU, 2017.

MILL, Daniel Ribeiro Silva. Gestão estratégica da Educação a distância: constituição, complexidades e desafios. IN: NEVES, Inajara de Salles, CORRADI, Wagner, CASTRO, Carmen Lúcia Freitas. EaD: Diálogos, compartilhamentos, práticas e saberes. Barbacena: Eduemg, 2016. P. $129-144$

MOORE, Michael; KEARSLEY, Greg. Educação a distância: uma visão integrada. São Paulo: Cengage Learning, 2010.

OECD. Education at a Glance: OECD indicators. OECD Publications, 2017. Disponível em: <http://download.inep.gov.br/acoes_internacionais/eag/documentos/2017/relatorio_education_at_a_glance_2017.pdf $>$. Consultado em: 09 fev. 2018.

OLIVEIRA, Caroline Mendes de. O tutor e a tutoria em Educação a Distância (EaD): O que dizem os últimos dez anos (2005-2015) de produção acadêmica? Belo Horizonte. Programa de Pós-Graduação em Educação da UFMG (Dissertação de Mestrado). 2017

Pinto, J. M. R. O que explica a falta de professores nas escolas brasileiras? Jornal de Políticas Educacionais, n. 15, jan-jun 2014. Disponível em: <http://www.jpe.ufpr.br/n15_1.pdf>. Consultado em: 10 fev. 2018.

\section{Notas}

\footnotetext{
${ }^{1}$ Em 2006 houve a constituição por meio de decreto, mas não o início de cursos a distância, que se dá pela oferta do curso de Administração, em parceria com o Banco do Brasil.

${ }^{2}$ Inúmeras associações profissionais manifestam-se contrárias à formação em nível de graduação a distância, tais como os de Engenharia e Agronomia, Enfermagem, Medicina e Direito. Observa-se nos dados do Censo de 2016 que cursos vinculados a Conselhos Nacionais possuem índices EaD muito menores do que aqueles que não os possuem - como é o caso das licenciaturas.
} 
Reflexões sobre a política nacional de formação de professores a distância e o enfraquecimento da EaD pública pela Universidade Aberta do Brasil (UAB)

* Professor do programa de Pós-Graduação em Educação da Universidade Federal de Minas Gerais, Belo Horizonte, Minas Gerais, Brasil.

\section{Correspondência}

Eucidio Pimenta Arruda - Universidade Federal de Minas Gerais. Av. Pres. Antônio Carlos, 6627 - Pampulha. CEP: 31270-901. Belo Horizonte, Minas Gerais, Brasil.

E-mail: eucidio@gmail.com

Recebido em 14 de maio de 2018

Aprovado em 27 de agosto de 2018

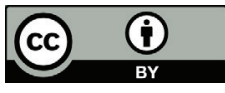

This work is licensed under a Creative Commons Attribution 4.0 International (CC BY 4.0). 
